\title{
Performance Evaluation of Sprayed Ductile Fiber-Reinforced Mortar as a Repairing Material
}

\author{
Su-Tae Kang, ${ }^{1)}$ Kyung-Taek Koh, ${ }^{2)}$ Gum-Sung Ryu, ${ }^{2)}$ Jin-Soo Kim, ${ }^{3)}$ and Cheon-Goo Han ${ }^{4)}$
}

(Received June 18, 2007, Revised, October 25, 2007, Accepted February 28, 2008)

\begin{abstract}
Most of existing repair materials have some shortcomings such as brittle fracture, imperfect interface bonding and marked difference in modulus of elasticity compared with the structures. These problems make their repair inefficient. Some researches on using a fiber-reinforced mortar as an alternative to enhance the efficiency have been carried out recently. This paper presents the results of an experimental study on the performance of sprayed PVA fiber-reinforced mortar as a repair material. We evaluated its mechanical properties, durability and strengthening effect. This study shows that the sprayed PVA fiber-reinforced mortar is remarkably effective as a repair material.
\end{abstract}

Keywords: repair, fiber reinforced, mortar, PVA fiber, spray.

\section{Introduction}

Various fiber-reinforced mortars made of large quantities of PVA fiber or steel fiber have been developed recently, and studies to find their applications in diverse domains are being conducted actively. ${ }^{1-4}$ With regard to its economical efficiency, the fiber-reinforced mortar of high toughness is more effective when it is applied as a repair material in small quantities rather than its casting of large volume as the main body of a structure in the field. The authors have developed a wet spraying technique using PVA fiber-reinforced ductile mortar and attempt to explore its use as a rehabilitation material. ${ }^{5,6}$ Spraying system is composed of mixer, mortar pump, air compressor, and spray gun as you can see in Fig 1. Owing to spray gun which has two steps to increase the air pressure, pumping efficiency can be improved. Consequently it can increase the bond strength and reduce the rebound of mortar. Unlike previous polymer-type or epoxy-type restorative materials, the coefficient of thermal expansion and the elastic modulus of the sprayed fiber-reinforced ductile mortar are similar to those of concrete, which allows it to behave similarly to the concrete members. In addition, the relatively small quantity of shrinkage of the material during and after hardening leads to remarkable dimen-

\footnotetext{
${ }^{1)}$ KCI Member, Structure Research Dept., Korea Institute of Construction Technology, Goyang 411-712, Korea.

E-mail: alphard@kict.re.kr

${ }^{2)}$ KCI Member, Structure Research Dept., Korea Institute of Construction Technology, Goyang 411-712, Korea.

${ }^{3} \mathrm{KCI}$ Member, Wonha Engineering \& Construction Co., Ltd., Uijeongbu 480-821, Korea.

${ }^{4)}$ KCI Member, Dept. of Architectural Engineering, Cheongju University, Cheongju 360-764, Korea.

Copyright (c) 2008, Korea Concrete Institute. All rights reserved, including the making of copies without the written permission of the copyright proprietors.
}

sional stability, making it possible to expect an increase in bond strength with the concrete structure. Moreover, the admixing of PVA fiber improves the flexural and tensile strength as well as the ductility and provides excellent resistance against impact loads, which is believed to enhance the load bearing capacity and the long-term durability. However, inadequate attention has been devoted by researchers to examine systematically the extent of the improvement brought by such fiber-reinforced ductile mortar comparing with existing restorative materials

and techniques. Accordingly, this study investigates the repair effects of the sprayed PVA fiber-reinforced mortar through estimation of its strength, shrinkage, change of mechanical properties before and after freezing and thawing cycles, as well as its durability and flexural performance in order to secure its stability for the use in the field.

\section{Experimental materials and methods}

\subsection{Materials}

Table 1 summarizes the features and types of the repair materials selected for the tests. A water to mortar ratio of 0.2 (W/M) has been set for all the repair materials. The sprayed PVA fiber-reinforced mortar is characterized by the admixing of $1.2 \%$ (by volume) of PVA fiber to the mortar composed of cement, fly-ash and CSA-type expansion agents. Table 2 shows the mix proportion of the sprayed PVA fiber-reinforced mortar and the characteristics of materials. The same tests have also been carried out on the existing product $\mathrm{R}$ using natural cellulose fiber in the mortar composed of polymer and the existing product $\mathrm{C}$ without the fiber in order to allow its comparison with the sprayed fiber-reinforced mortar.

\subsection{Test methods}

Compression, tension, bond and impact tests were conducted in order to examine the strength characteristics of the sprayed fiber- 


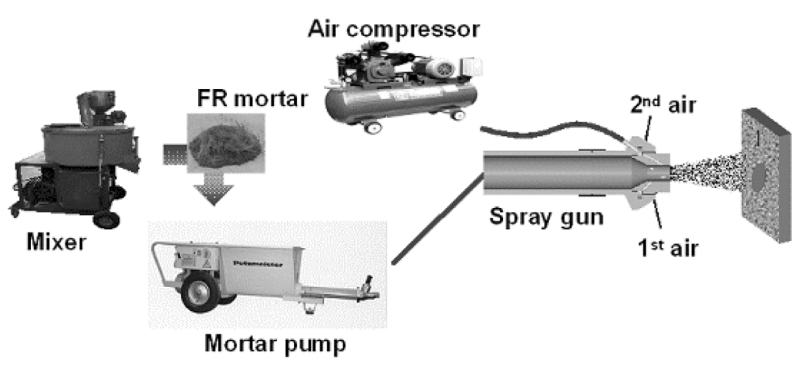

Fig. 1 Spraying system.

reinforced mortar. The strength test was performed after water curing and at a pre-determined age. Plastic shrinkage, autogenous shrinkage and drying shrink age tests were also executed. Additionally, a confined drying shrinkage test was performed to evaluate the crack control performance. The change in mechanical properties has been examined by means of freezing-thawing cycle tests. The durability has been examined by means of carbonation, salt attack and freezing-thawing cycle tests. The carbonation depth was measured at pre-determined ages using a $1 \%$ phenolphthalein solution on $\varphi 100 \times 100 \mathrm{~mm}$ specimens exposed to $5 \%$ concentration of $\mathrm{CO}_{2}$, temperature of $30^{\circ} \mathrm{C}$ and humidity of $50 \%$ after 14 days of water curing. The resistance to salt attack was tested according to ASTM C 1202 on a $\varphi 100 \times 50 \mathrm{~mm}$ specimen with epoxy coating applied on the lateral faces after 14 days of water curing. The resistance to freezing and thawing cycles was examined according to ASTM C 666-B, and the corresponding relative
Table 2 Mix proportion of PVA fiber-reinforced mortar and the characteristics of materials.

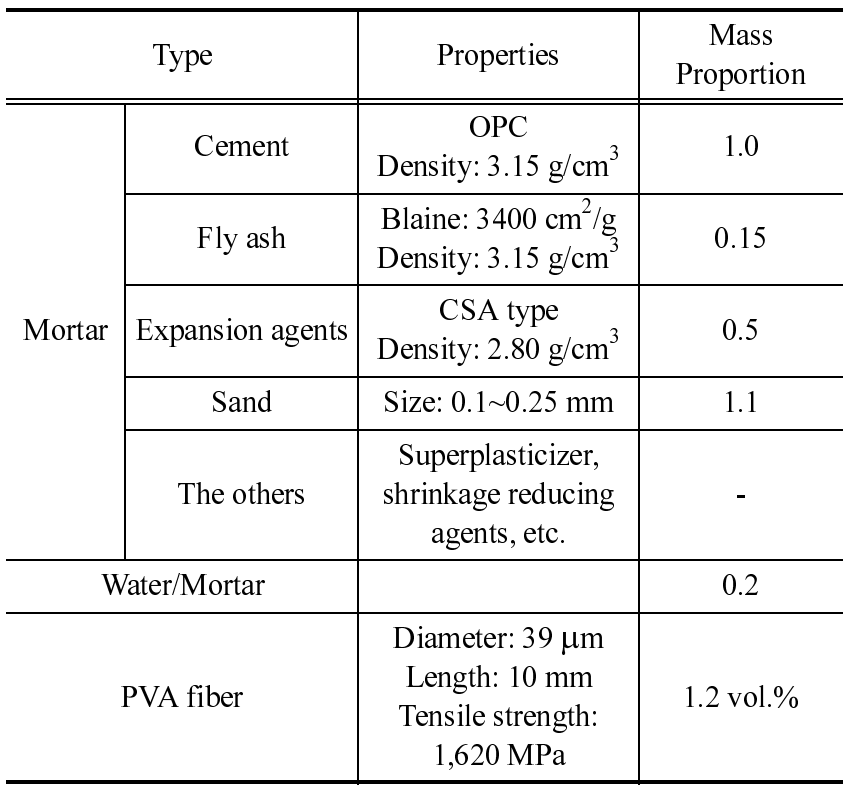

dynamic modulus of elasticity was evaluated. The flexural strength and bond strength were measured before and after the freezing and thawing test. The details of each method are summarized in Table 3.

Specimens with dimensions of $300 \times 300 \times 2,400 \mathrm{~mm}$ were manufactured as shown in Fig. 2 in order to examine the flexural

Table 1 Features of the tested repair materials.

\begin{tabular}{c|c|c|c}
\hline Type & Components of mortar & Fiber & Main Purpose \\
\hline \hline Sprayed PVA fiber-reinforced mortar & Inorganic materials & PVA fiber & Repair/ reinforcement \\
\hline Product R & 3 component-type polymer resin & Natural cellulose fiber & Crack and spalling repair, filling \\
\hline Product C & SBR-type polymer & No fiber & Rust proof/restoring \\
\hline
\end{tabular}

Table 3 Details of each test method.

\begin{tabular}{|c|c|c|c|}
\hline Properties & Testing Method & Specimen & Condition \\
\hline Compressive strength & KS L 5105 & $50 \times 50 \times 50 \mathrm{~mm}$ & \multirow{4}{*}{ Curing at $20 \pm 3^{\circ} \mathrm{C}$ for 28 days } \\
\hline Tensile strength & KS L 5104 & Dog-bone shaped & \\
\hline Bond strength & KS F 4042 & - & \\
\hline Impact strength & KS F 2221 & - & \\
\hline Plastic shrinkage & PVC-Ring Method & $500 \times 500 \times 500 \mathrm{~mm}$ & $\begin{array}{c}\text { Temperature: } 30 \times 3^{\circ} \mathrm{C} \\
\text { Humidity: } 40 \times 3 \% \\
\text { Wind : } 4 \sim 4.5 \mathrm{~m} / \mathrm{sec}, 24 \text { hours }\end{array}$ \\
\hline Autogenous shrinkage & KS F 2586 & \multirow{2}{*}{$100 \times 100 \times 400 \mathrm{~mm}$} & \multirow{3}{*}{$\begin{array}{c}\text { Temperature: } 20 \pm 3^{\circ} \mathrm{C} \\
\text { Humidity: } 60 \pm 5 \%\end{array}$} \\
\hline Drying shrinkage & KS F 2424 & & \\
\hline Crack resistance & KS F 2595 & - & \\
\hline
\end{tabular}
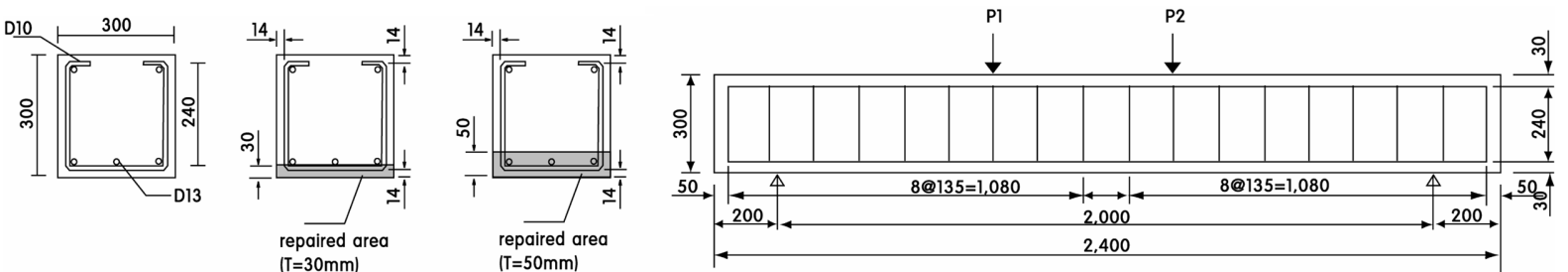

Fig. 2 Specimens for flexural tests 
load bearing capacity of the repaired structure with the sprayed fiber-reinforced mortar. Repaired structures were made by applying the mortar after removing the area to be repaired. Table 4 summarizes the details of the specimens and the applied techniques. Two non-reinforced (plain) specimens were manufactured. Three specimens were fabricated with the sprayed fiber-reinforced mortar to possess a reinforcement thickness of $30 \mathrm{~mm}$ and $50 \mathrm{~mm}$ with proportions of PVA fiber set to $1.2 \%$ and $1.5 \%$, respectively. Specimens with used polymer-type repair mortar and one layer of carbon fiber sheet, widely used for rehabilitation purpose, were also manufactured for the comparison with the specimen with sprayed fiber-reinforced mortar. Carbon fiber sheet has the depth of $0.11 \mathrm{~mm}$, tensile strength of $3,550 \mathrm{MPa}$, and elastic modulus of $235 \mathrm{GPa}$. The concrete used for the specimens used coarse aggregates with the maximum dimension of $25 \mathrm{~mm}$ and exhibited design strength of $24 \mathrm{MPa}$. Steel rebars of $13 \mathrm{~mm}$ diameter with yield strength of $350 \mathrm{MPa}$ were also used.

\section{Experimental results}

\subsection{Strength properties}

Fig. 3 plots the compressive strength according to the type of repair material. The sprayed fiber-reinforced mortar exhibits remarkably higher tensile strength than existing repair materials. This is due to the high strength of the repair mortar itself and to the use of PVA fiber, which increases the tensile strength significantly. Fig. 4 compares the elastic modulus of the sprayed fiber-reinforced mortar with those obtained by existing predictive formula. It can be seen that the elastic modulus of the material is underestimated compared to the values predicted by the formulae proposed by the Korean concrete structural design specifications and by the ACI Committee 363. However, this modulus is slightly larger than that obtained through the formula proposed in the design and construction guidelines for high-performance fiber reinforced cementitious composites (HPFRCC) of the Japanese Society of Civil Engineers under the condition of the same strength. ${ }^{1}$ The elastic modulus of HPFRCC in these guidelines was $1 / 2-2 / 3$ of ordinary concrete. On the other hand, considering the fact that repair is unnecessary for high strength structures and assuming that structures requiring repair generally uses the concrete with strength below $30 \mathrm{MPa}$, it can be said that the elastic modulus of the sprayed fiber-reinforced mortar is similar to that of concrete structures requiring repair.

Fig. 5 presents the resistance to impact according to the type of repair material. All of the existing repair materials failed before $50^{\text {th }}$ free dropping cycles, which reveals their brittle fracture mode. However, the first micro-crack appeared at the $97^{\text {th }}$ free dropping

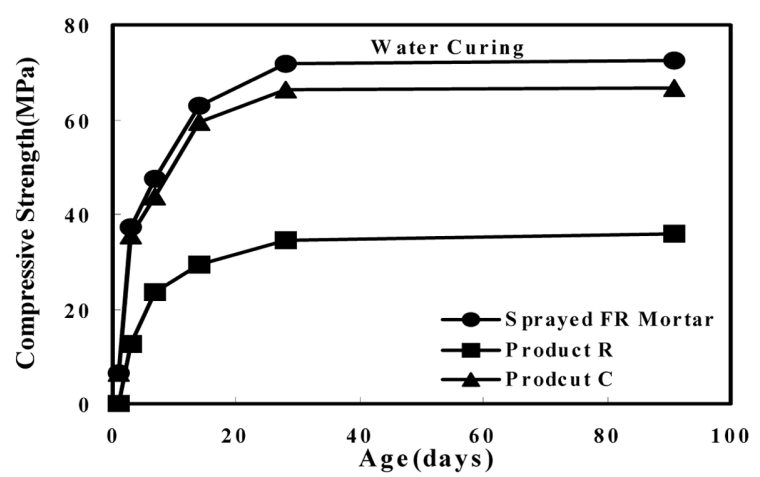

(a) Compressive strength

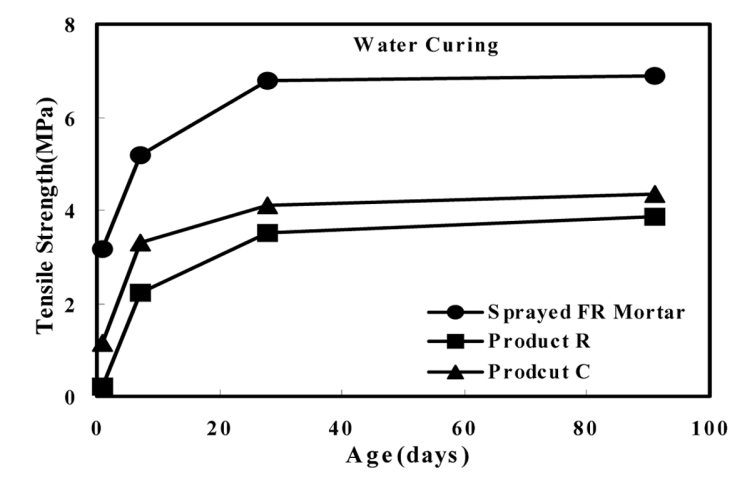

(b) Tensile strength

Fig. 3 Compressive and tensile strengths according to the type of repair material.

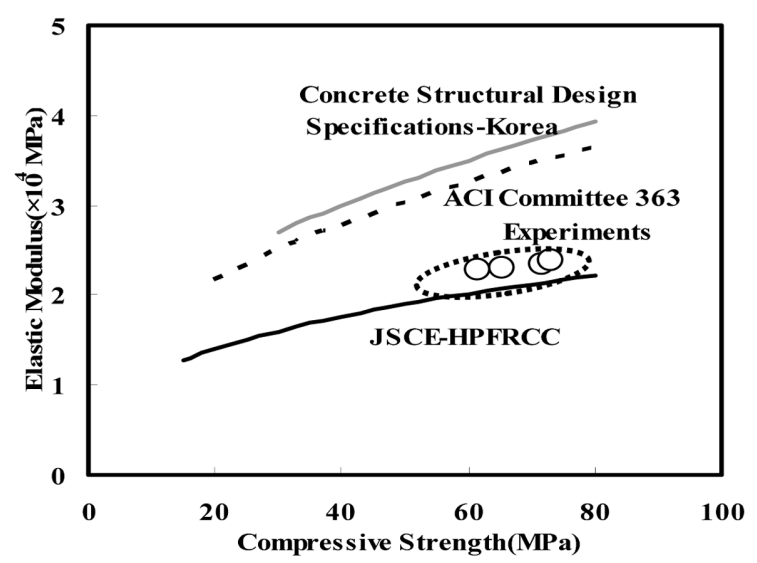

Fig. 4 Comparison of the elastic moduli of the sprayed fiberreinforced mortar predicted by existing methods.

cycle for the sprayed fiber-reinforced mortar without the appearance of other cracks or failure up to the $500^{\text {th }}$ cycle. Such remark-

Table 4 Features of the tested repaired materials.

\begin{tabular}{c|c|c|c|c|c}
\hline \multicolumn{2}{c|}{ Classification } & Notation & Number of specimens & Dimensions & Volume fraction of fiber $\left(\mathrm{V}_{\mathrm{f}}\right)$ \\
\hline \hline \multicolumn{2}{c|}{ Standard specimen } & Plain & 2 & Standard specimen & - \\
\hline \multirow{4}{*}{ Repairing } & \multirow{3}{*}{$\begin{array}{l}\text { Sprayed fiber-rein- } \\
\text { forced(FR) mortar }\end{array}$} & VF1.5-T30 & 1 & $\mathrm{~T}=30 \mathrm{~mm}$ & $1.5 \%$ \\
\cline { 3 - 6 } & & VF1.2-T50 & 1 & $\mathrm{~T}=50 \mathrm{~mm}$ & $1.2 \%$ \\
\cline { 2 - 6 } & The existing & PF1.5-T50 & 1 & $\mathrm{~T}=50 \mathrm{~mm}$ & $1.5 \%$ \\
\hline Reinforcement & The existing & Carbon fiber sheet & 1 & 1 layer reinforced & - \\
\hline
\end{tabular}




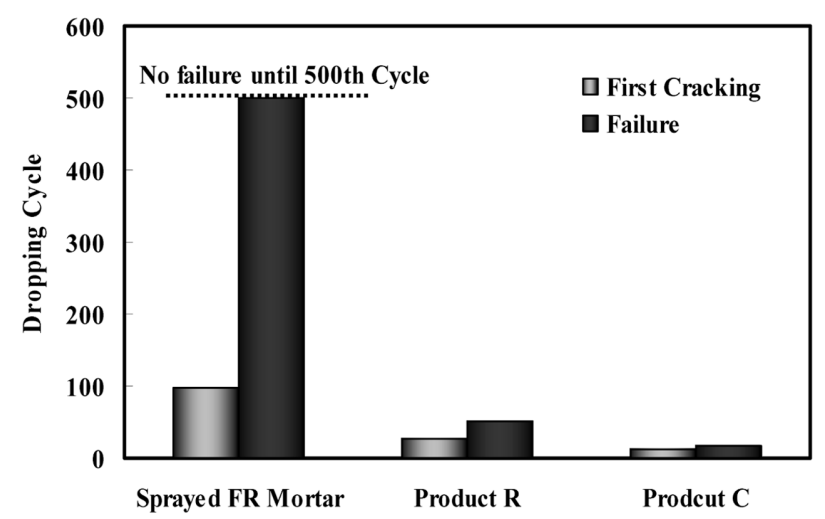

Fig. 5 Impact strength according to the type of repair material.

able resistance to impact of the sprayed fiber-reinforced mortar can be explained by the improvement of the shock absorption performance due to the mixing of PVA fiber into the test specimen.

\subsection{Shrinkage properties}

Table 5 summarizes the results of the plastic shrinkage test and Fig. 6 shows images of specimens after plastic shrinkage. The existing products $\mathrm{R}$ and $\mathrm{C}$ developed cracks of about 56 and $715 \mathrm{~mm}^{2}$, respectively, under plastic shrinkage, while the sprayed fiber-reinforced mortar did not manifest any crack.

Fig. 7 summarizes the results of the autogenous and drying shrinkage test. The autogenous and drying shrinkage strains, developed by the sprayed fiber-reinforced mortar, appear to be smaller by about $30 \sim 40 \%$ and $20 \%$, respectivey, compared to those of existing repair materials. The small shrinkage developed in the sprayed fiber-reinforced mortar is due to the use of shrinkage reducing agents and CSA-type expansion agents as well as the admixing of PVA fiber.

Fig. 8 arranges the result of the crack control performance according to the type of repair material. The products $\mathrm{C}$ and $\mathrm{R}$ developed cracks after approximately 10 days, and cracks appeared after 13 days for the sprayed fiber-reinforced mortar. The product $\mathrm{R}$ and $\mathrm{C}$ experienced cracks at first to present brittle cracking mode while the sprayed fiber-reinforced mortar exhibited ductile cracking mode without the large development of cracks even after first cracking owing to the bridging action of the PVA fiber.

Table 5 Plastic shrinkage test results according to the type of repair material

\begin{tabular}{c|c|c|c|c|c}
\hline \multirow{2}{*}{ type } & \multicolumn{5}{|c}{ Crack properties } \\
\cline { 2 - 5 } & No. & $\begin{array}{c}\text { Length } \\
(\mathrm{mm})\end{array}$ & $\begin{array}{c}\text { Width } \\
(\mathrm{mm})\end{array}$ & $\begin{array}{c}\text { Area } \\
\left(\mathrm{mm}^{2}\right)\end{array}$ & $\begin{array}{c}\text { Total area } \\
\left(\mathrm{mm}^{2}\right)\end{array}$ \\
\hline \hline $\begin{array}{c}\text { Sprayed } \\
\text { FR mortar }\end{array}$ & \multicolumn{5}{|c}{ No crack } \\
\hline \multirow{3}{*}{ Product R } & $1^{*}$ & 100 & 0.5 & 50 & \multirow{2}{*}{56} \\
\cline { 2 - 5 } & $2^{*}$ & $20 \sim 60$ & 0.1 & $2 \sim 6$ & \\
\hline \multirow{4}{*}{ Product C C } & $1^{*}$ & 190 & 2 & 380 & \multirow{2}{*}{715} \\
\cline { 2 - 5 } & $2^{*}$ & 150 & 1 & 150 & \\
\cline { 2 - 5 } & $3^{*}$ & 160 & 1 & 160 & \\
\cline { 2 - 5 } & $4^{*}$ & 50 & 0.5 & 25 & \\
\hline
\end{tabular}
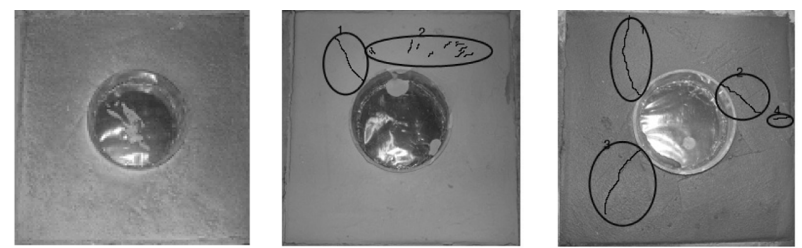

(a) Sprayed FR mortar

(b) Existing product $\mathrm{R}$

(c) Existing product $\mathrm{C}$

Fig. 6 Images of specimens after plastic shrinkage test.

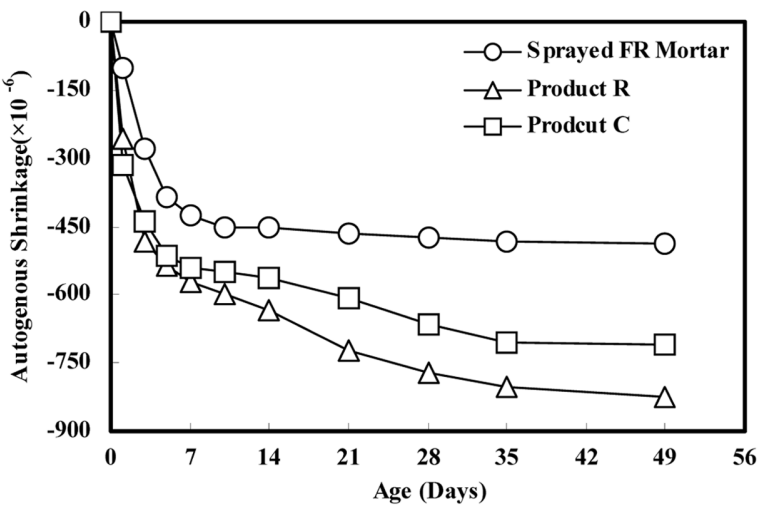

(a) Autogenous shrinkage

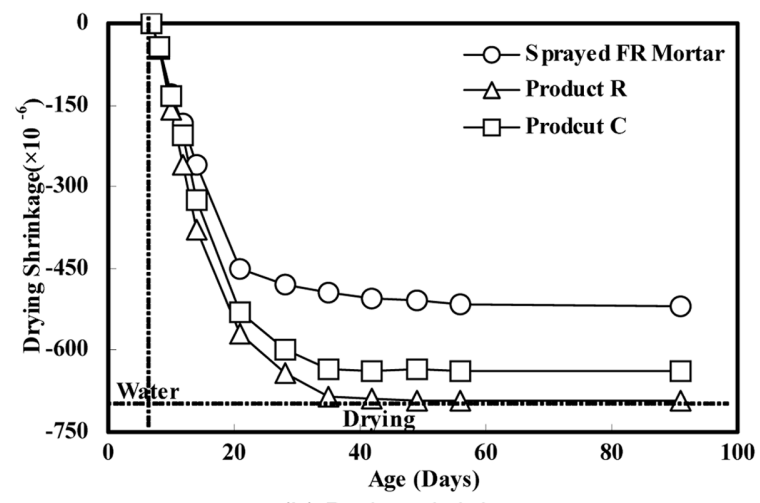

(b) Drying shrinkage

Fig. 7 Shrinkage characteristics according to the type of repair material.

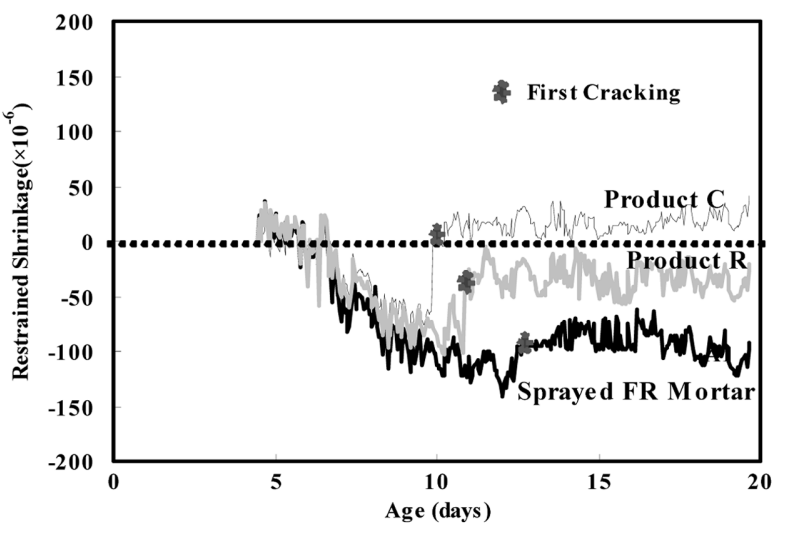

Fig. 8 Strains on the specimens due to confining shrinkages.

\subsection{Durability}

The resistance against carbonation was evaluated by the criteria set forth by KS F 4042. Fig. 9 shows the carbonation depth according to the type of repair material. The results show that the 
sprayed fiber-reinforced mortar not only satisfy the criteria and but also is more resistant compared with product $\mathrm{R}$ and $\mathrm{C}$.

Fig. 10 presents the analysis results with respect to the resistance to salt attack. Regardless of the repair technique, all the results were evaluated as "very low" according to the criteria proposed by KS F 2711. Even though all the experimental values satisfied the KS F 4042 to be below the electric charge of 1,000 Coulombs, the standard for the repair materials in Korea, the sprayed fiber-reinforced mortar appears to exhibit the most resistance to salt attack among all the considered repair methods.

The results for the relative dynamic modulus of elasticity are summarized in Fig. 11. The product $\mathrm{R}$ exhibited degraded resistance to freezing and thawing after the first cycle, with a $60 \%$ decrease in relative dynamic modulus of elasticity at the failure state after 120 freezing-thawing cycles. On the other hand, the sprayed fiber- reinforced mortar and the product $\mathrm{C}$ presented a remarkable relative dynamic modulus of elasticity, exceeding $80 \%$ even after 300 cycles at the completion of freezing-thawing. Especially, the sprayed fiber-reinforced mortar exhibited superior resistance to freezing-thawing with a relative dynamic modulus of elasticity of $98 \%$.

Fig. 12 plots the variation of the flexural strength before and after the freezing-thawing test. Even if the existing products without the fiber reinforcement satisfied the criteria of KS F 4042 before the test, their flexural strength dropped below $6 \mathrm{MPa}$ after the completion of the test. However, the sprayed fiber-reinforced

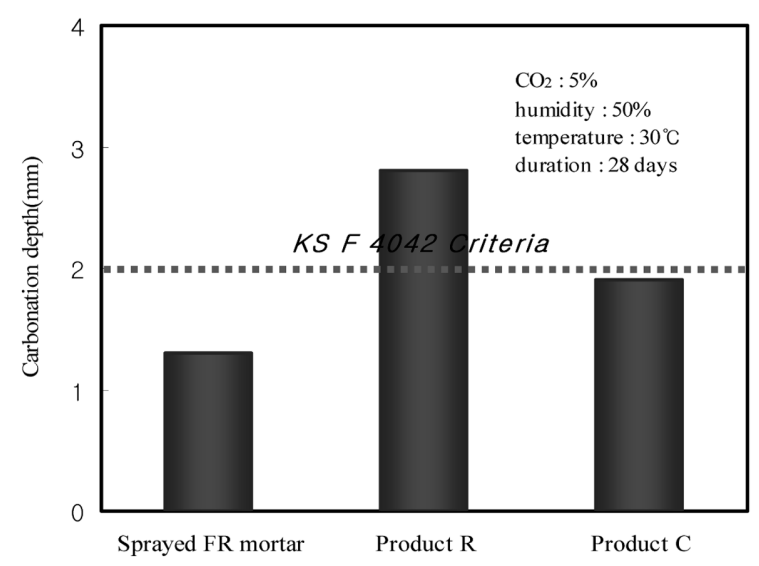

Fig. 9 Evaluation of the resistance to carbonation according to the type of repair material.

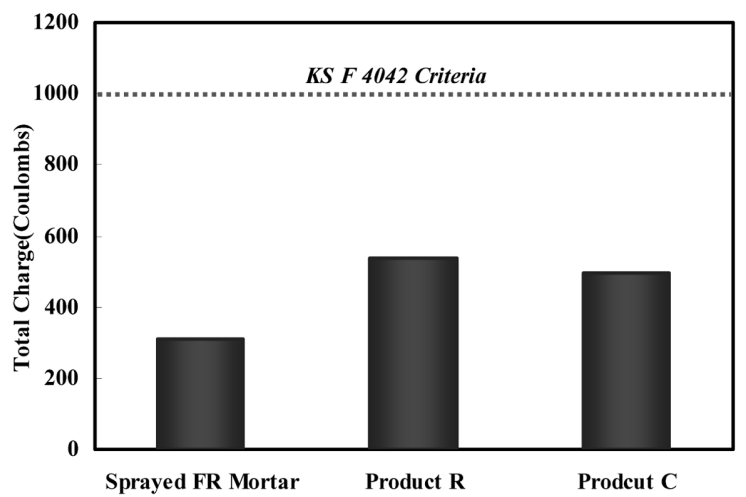

Fig. 10 Evaluation of the resistance to salt attack according to the type of repair material. mortar showed an insignificant variation of the flexural strength before and after the freezing-thawing test, thus satisfying the KS standards. Consequently, the existing products exhibit degradation due to the action of freezing-thawing leading to the drop of the flexural strength below the KS criteria, which is likely to initiate cracking in the repair layer, while the sprayed fiber-reinforced mortar appears to be immune to the action of freezing and thawing.

Fig. 13 depicts the experimental results for the bond strength before and after freezing-thawing cycles. The test was repeated for 300 cycles. Before the start of freezing and thawing cycles, all the

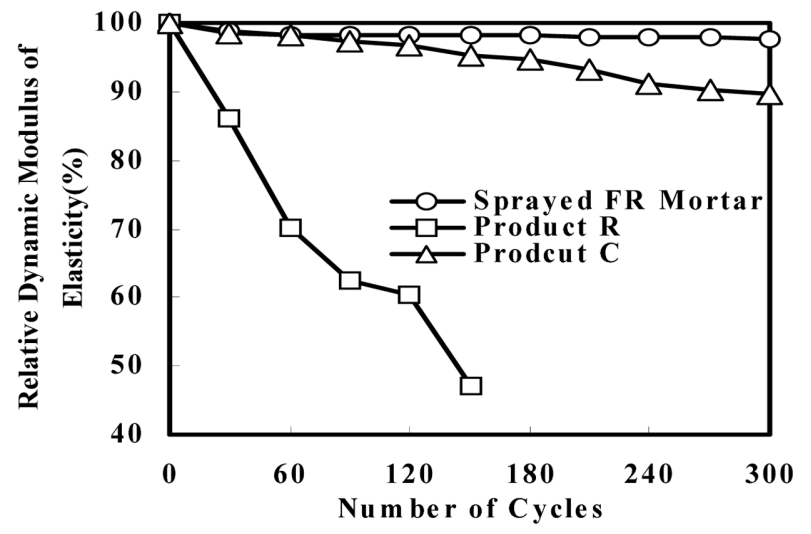

Fig. 11 Results of relative dynamic modulus of elasticity.

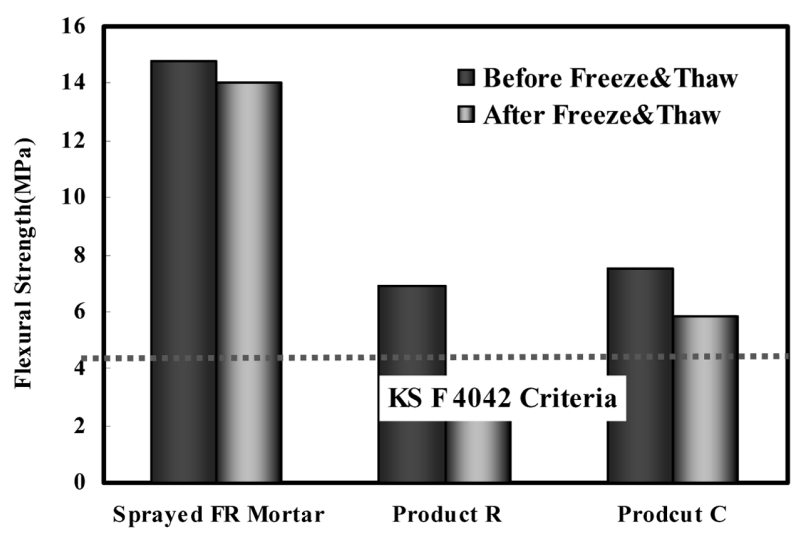

Fig. 12 Change in the flexural strength before and after freezing-thawing test.

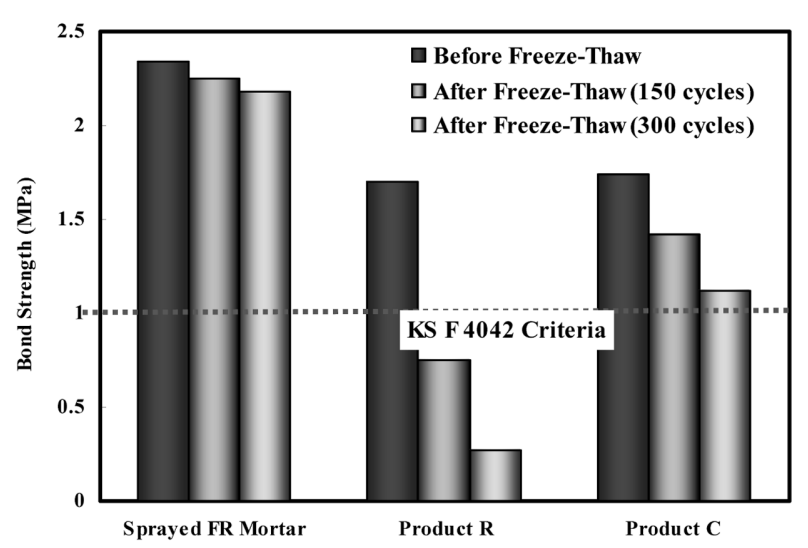

Fig. 13 Comparison of Bond Strength before and after freezing-thawing cycles. 
materials satisfied the criteria of KS F 4042, which specifies that the repair material should be over than $1 \mathrm{MPa}$ in bond strength. Especially, the sprayed fiber-reinforced mortar exhibited 1.35 times higher bond strength than that of compared materials. But after the freezing and thawing cycles, product $\mathrm{R}$ showed decreased bond strength to be below the criteria at 150 cycles and resulted in nearly zero bond strength at 300 cycles. Moreover, Product $\mathrm{C}$ showed a barely noticeable decrease in bond strength while satisfying the criteria both at 150 and 300 cycles. On the other hand, the sprayed fiber-reinforced mortar hardly showed a difference in the bond strength before and after the freezing-thawing cycles.

\subsection{Flexural performance}

The compressive strength of normal concrete was $26.4 \mathrm{MPa}$. The sprayed fiber-reinforced mortar, product $\mathrm{R}$ and product $\mathrm{C}$ had compressive strength of $68.6 \mathrm{MPa}, 31.2 \mathrm{MPa}$ and $64.3 \mathrm{MPa}$, respectively. Table 6 summarizes the results of the load-displacement relationship of the beam specimen and the strain of the tension rebar. Figure 14 and Figure 15 plot the corresponding curves. Assuming the yield strength of $f_{y}=350 \mathrm{MPa}$ for the main rebar of $13 \mathrm{~mm}$ diameter, the yield load of the main rebar is defined as the load $P_{y}$ for which the yield strain $\mu_{e}$ is equal to 1,750 . In addition, the yield load of the reinforced specimen is expressed in terms of the ratio of the yield loads of the carbon reinforced specimen $\left(P_{y}\right)$ to those of the specimen without the reinforcement.

Since both the strength and the stiffness of the specimens using existing repair materials are not exhibiting any increase compared to the reference non-reinforced specimen, it is likely that no reinforcement effect should be expected for the specimens using existing repair materials. The specimen bonded with one layer of carbon fiber sheet, which corresponds to the reinforcement methods widely selected recently, is showing a reinforcement effect with an increase of $50.7 \%$ in the maximum strength compared to the reference specimen. However, debonding of the sheet occurs suddenly at a displacement of $15.6 \mathrm{~mm}$, which reveals a significant reduction in the ductility. Accordingly, even if the carbon fiber sheet reinforcement technique results in a reinforcement effect with respect to the load bearing capacity at early construction, a careful attention should be paid to the sudden failure at the interface between the sheet and concrete that eventually leads to a brittle fracture at failure.

The increase in the maximum strength and stiffness was verified for all of the 3 specimens using the sprayed fiber-reinforced

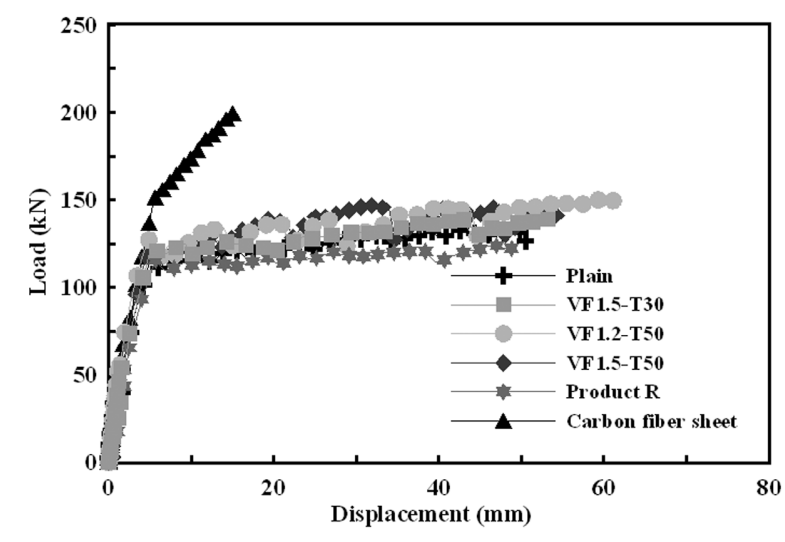

Fig. 14 Load-displacement relationships.

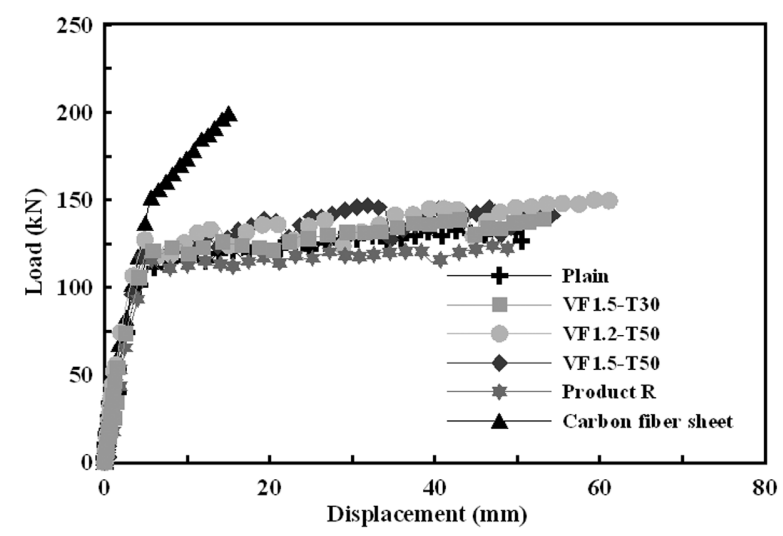

Fig. 15 Relationships of load versus strain of the rebar.

mortar. Among these specimens, the one with admixing of $1.5 \%$ fiber in the 50mm-thickness reinforcement manifested the largest increase in the maximum strength, corresponding to an augmentation of about $15 \%$ compared to the reference specimen as well as an approximately $17 \%$ increase in the yield strength. In addition, the yield strain increased by 1.2 times compared to the reference specimen regardless of the type of the specimens and the proportion of fiber and reinforcement thickness. Consequently, regarding the fact that the sprayed fiber-reinforced mortar also exhibits reinforcement effect and considering the durability and load bearing capacity globally, the sprayed fiber-reinforce mortar is evaluated to be sufficiently effective as a material combining both rehabilitation and reinforcement effects.

Table 6 Structural test results.

\begin{tabular}{c|c|c|c|c|c|c}
\hline \multirow{2}{*}{ Specimen } & \multicolumn{3}{|c|}{ Load-displacement results } & \multicolumn{3}{c}{ At yielding of tension rebar } \\
\cline { 2 - 7 } & $\begin{array}{c}\text { Max. load } \\
(\mathrm{kN})\end{array}$ & $\begin{array}{c}\text { Yield load } \\
(\mathrm{kN})\end{array}$ & $\begin{array}{c}\text { Yield displ. } \\
(\mathrm{mm})\end{array}$ & \multirow{2}{*}{$P_{y}(\mathrm{kN}$, mean $)$} & $\begin{array}{c}\text { Reinforced/ } \\
\text { Non-reinforced }\end{array}$ & $\begin{array}{c}\text { Reinforced/ } \\
\text { Carbon fiber sheet }\end{array}$ \\
\hline \hline plain 1 & 133.58 & 98.6 & 3.99 & 98.2 & 1.00 & 0.77 \\
\hline plain 2 & 129.89 & 97.9 & 4.19 & 121.7 & 1.24 & 0.95 \\
\hline VF1.5-T30 & 140.89 & 121.7 & 5.04 & 117.9 & 1.20 & 0.92 \\
\hline VF1.2-T50 & 148.95 & 117.9 & 4.57 & 121.0 & 1.23 & 0.95 \\
\hline VF1.5-T50 & 151.87 & 121.0 & 4.27 & 99.3 & 1.01 & 0.78 \\
\hline Product R & 125.09 & 99.3 & 4.57 & 127.6 & 1.30 & 1.00 \\
\hline Carbon fiber sheet & 201.35 & 127.6 & 4.52 & & & 0 \\
\hline
\end{tabular}




\section{Conclusions}

In order to explore the use of high-toughness fiber-reinforced mortar mixed with PVA fiber as a repair material, its strength, shrinkage characteristics and the change in mechanical properties before and after freezing-thawing cycles as well as the flexural performance of beam specimens were compared with those of existing repair materials, and the results are summarized in the following.

1) The sprayed fiber-reinforced mortar exhibited the strength, elastic modulus, bond and impact load significantly superior to existing repair materials.

2) The sprayed fiber-reinforced mortar did not initiate cracking under plastic shrinkage but manifested an approximately $30 \%$ reduction in the autogenous and drying shrinkages compared to existing repair materials. It also exhibited such a remarkable dimensional stability as its exceptional crack control performance.

3) The sprayed fiber-reinforced mortar presented no definite difference in the flexural and bond strength before and after freezing-thawing cycles, while the existing repair materials exhibited a considerable reduction in their bond and flexural strength.

4) The sprayed fiber-reinforced mortar showed not only a significant improvement in the load bearing capacity compared to exiting restorative materials but also enhanced the ductility without the occurrence of interfacial failure or brittle fracture. The sprayed fiber-reinforced mortar also exhibited a reinforcement effect similar to an existing reinforcement method (95\% of the reinforcement effect of one layer carbon fiber sheet).

\section{Acknowledgements}

This research was supported by a grant (05CCTRD09 - High Performance Construction Material Research Center) from Construction Core Technology Program funded by Ministry of Construction \& Transportation of Korean government and WONHA Engineering \& Construction Co., Ltd.

\section{References}

1. JSCE Concrete Committee: Evaluation and Using of High Performance Fiber Reinforced Cementitious Composites, Concrete Engineering Series, 64, JSCE, 2005.

2. Naaman, A. E. and Reinhardt, H. W., High Performance Fiber Reinforced Cement Composites 2 (HPFRCC2), E\&FN SPON, 1995.

3. Li, V. C. "High Performance Applications of Fibers in Civil Engineering," Journal of Applied Polymer Science, Vol. 83, 2002.

4. Koh, K. T. et al., Development of the Advanced Technology of Durability in Concrete Bridges, Korea Institute of Construction Technology (KICT), 2005.

5. Lee, G. C. et al.: Fundamental Properties of Fiber Composite Spray Mortar, Proceedings of the Korea Concrete Institute, Vol. 18, No. 2, 2006, pp. 305 308.

6. Ryu, G S. et al., "A Study on the Evaluation for Durability Performance of the Repair Method Using Fiber Reinforced Mortar," Proceedings of the Korea Concrete Institute, Vol. 18, No. 2 , 2006, pp 291 314. 